\title{
A REAL TIME BUILDING ENERGY EFFECTIVENSS ASSESSMENT MODEL
}

\author{
Min Wu \\ Dept. of Real Estate and Construction, University of \\ Hong Kong, Pokfulam Road, Hong Kong Email: \\ minwu@hku.hk
}

\author{
Daniel C.W. Ho \\ Dept. of Real Estate and Construction, University of \\ Hong Kong, Pokfulam Road, Hong Kong \\ Email: danielho@hku.hk
}

\begin{abstract}
While building provides shelter for human being, the previous models for assessing the intelligence of a building seldom consider the responses of occupants. In addition, the assessment is usually conducted by an authority organization on a yearly basis, thus can seldom provide timely assistance for facilities manager to improve and maintain their system. After a critical review of the models in a previous published paper regarding building intelligence assessment, this study develops a sensor based real time office building energy effectiveness assessment model. The new model considers both the energy consumption of the building and the responses of its occupants. A case study demonstrates how the model can be implemented. Code is provided as well.
\end{abstract}

\section{KEYWORDS}

Real-time, energy consumption, building, assessment

\section{BACKGROUND}

In the last two decades, intensive research has been done in the area of intelligent buildings (IBs) $[1,2]$. One important topic in IB research is building intelligence assessment, as it may lead to methods for evaluating new and existing building designs, and assists the building manager in monitoring the 'health' of the building. There are a number of IB assessment systems available now [3-7]. Over 45 per cent of energy is consumed by buildings which arise from the embodied energy in materials and the operational energy for running its building service systems. Whilst these IB assessment systems assess the building and its systems; none of them has sufficiently addressed the total energy consumption of IBs. To address this issue, a recent study [8] proposed a life span energy efficiency approach using an analytic network process (ANP) model. The decision model, called IB Assessor, was developed using a set of lifespan energy performance indicators selected by using an energytime consumption index ( ETI ). However, it seems that the models in [8] need to be improved.

\section{A CRITICAL REVIEW OF THE MODELS IN CHEN ET AL. [8]}

Previous life cycle analysis/assessment (LCA) studies $[9,10]$ suggest that the life span of a building 
consists of a number of successive stages in building design, construction, commission, operation relevant to their structural and services system, and demolition. While claiming that they were "lifespan energy efficiency approaches", the models in [8] did not encompass energy consumption in building demolition. Furthermore, their embodied energy consumption rate model, together with their method for the calculation of that embodied energy consumption rate, could be improved significantly.

\section{Their embodied energy consumption rate model}

The authors in Chen et al. [8, p.400] defined the embodied energy consumption rate as ETI. The $E T I$ function $\left(F_{E T I}\right)$ was proposed as:

$$
F_{E T I}=f(e, t)
$$

where $e$ was energy, $t$ was time. Their theoretical method to calculate the ETI for an indicator $i\left(E T I_{i}\right)$ was proposed as a partial time derivative of the Eq (1), and was given by:

$$
E T I_{i}=\frac{\partial F_{E T I_{I}}}{\partial t}
$$

Their practical method to calculate the $E T I_{i}$ was proposed as:

$$
E T I_{i}=\frac{S E C_{i}}{S T C_{i}}=\frac{S E C_{i, 1}+S E C_{i, 2}}{S T C_{i, 1}+S T C_{i, 2}}
$$

where $S E C_{i}$ was the score of energy consumption of indicator $i, S T C_{i}$ was the score of time consumption of indicator $i, S E C_{i, 1}$ was the score of the embodied energy consumption of indicator $i$, $S E C_{i, 2}$ was the score of the operational energy consumption of indicator $i, S T C_{i, 1}$ was the score of the time consumption of indicator $i$ for its manufacture, transportation, and installation, $S T C_{i, 2}$ was the score of the time consumption of indicator $i$ for its operation.
Eq. (3) and Eq. (2) suggest that the variable $F_{E T I}$ has the same unit as that of energy. However, Eq. (1) suggests that the variable $F_{E T I}$ is a combination of two variables which are energy and time. Eqs (3) and (2) thus contradict with Eq. (1). It seems that $e$ in Eq. (1) might be energy consumption rate. But, if $e$ is the energy consumption rate, then ETI in Eq. (2) should be $e$. In addition, Eq. (3) shows that operational energy is included in both $F_{E T I}$ in Eq. (1) and $E T I_{i}$ in Eq. (2). Operational energy and embodied energy are two distinct concepts. Hence, it is not appropriate for ETI to be called as "embodied energy consumption rate" $[8, \mathrm{p} .400]$.

Their practical method for calculating the embodied energy consumption rate

Following the proposal of their so called "practical method for calculating the embodied energy consumption rate", Chen et al. [8] subjectively defined the fundamental scales for score of energy consumption ( $S E C$ ) and score of time consumption ( STC ) (see Table 1).

Based on their fundamental scales for energy and time consumption, the researchers provided $E T I_{i}$ for 43 indicators (see Table 2). To analyze their data, these indicators have been regrouped.

The researchers estimated that the scope of ETI was between 20 and 1000 (see Table 2). They then used Gann's square of nine to select a group of Key performance indicators (KPIs) (see Table 3)

There are a number of inconsistence among Tables 1 to 3 and Eq. (3). Firstly, the fundamental scales of $S E C$ and $S T C$ in Table 1 haven't been designed properly. For example, Table 2 shows that the $S E C$ and STC for "construction materials", the 1 st indicator are 16 and 9 respectively. However, neither 16 for $S E C$ nor 9 for $S T C$ has been defined in Table 1. In addition, for STC, Table 2 also shows that $1+2=3$, see "waste disposal", the 21 st indicator. Does $(0,1$ day $)+(1$ day, 1 week $)=$ (1 week, 1 month)? To address this problem, a fuzzy approach might be a better solution. 
Table 1. Fundamental scales of $S E C$ and $S T C$

\begin{tabular}{|c|c|c|c|}
\hline \multicolumn{2}{|c|}{ Scales for scoring } & Product & Process \\
\hline \multicolumn{2}{|c|}{ Score of energy consumption $\left(S E C_{i}\right)$} & \multirow{6}{*}{$\begin{array}{c}S E C_{i, 1} \\
\text { Embodied energy of } \\
\text { products in manufacture, } \\
\text { construction and } \\
\text { installation }\end{array}$} & \multirow{6}{*}{$\begin{array}{l}\qquad S E C_{i, 2} \\
\text { Energy required in } \\
\text { operation processes upon } \\
\text { People' occupancy } \\
\text { requirement }\end{array}$} \\
\hline $1=$ extremely low & $6=$ high & & \\
\hline $2=$ very strongly low & $7=$ moderately high & & \\
\hline $3=$ strongly low & $8=$ strongly high & & \\
\hline $4=$ moderately low & $9=$ very strongly high & & \\
\hline $5=$ low & $10=$ extremely high & & \\
\hline \multicolumn{2}{|c|}{ Score of time consumption $\left(S T C_{i}\right)$} & \multirow{4}{*}{$\begin{array}{l}\qquad S T C_{i, 1} \\
\text { Time required for product } \\
\text { in manufacture, } \\
\text { construction and } \\
\text { installation } \\
\end{array}$} & \multirow{4}{*}{$\begin{array}{c}\qquad S T C_{i, 2} \\
\text { Time required in } \\
\text { operation processes upon } \\
\text { People' occupancy } \\
\text { requirement }\end{array}$} \\
\hline $1=(0,1$ day $)$ & $4=(1$ month, 1 year $)$ & & \\
\hline $2=(1$ day, 1 week $)$ & $5=>1$ year & & \\
\hline $3=(1$ week, 1 month $)$ & & & \\
\hline
\end{tabular}

Table 2. Indicators and their $E T I_{i}$ values

\begin{tabular}{|c|c|c|c|c|c|c|c|c|}
\hline & Indicator & $S E C_{i, 1}$ & $S E C_{i, 2}$ & $S E C_{i}$ & $S T C_{i, 1}$ & $S T C_{i, 2}$ & $S T C_{i}$ & $E T I_{i}$ \\
\hline 1 & Construction materials & 8 & 8 & 16 & 4 & 5 & 9 & 178 \\
\hline 2 & Green materials & 5 & 5 & 10 & 3 & 5 & 8 & 125 \\
\hline 3 & $\begin{array}{c}\text { Electricity and electrical } \\
\text { services }\end{array}$ & 7 & 5 & 12 & 1 & 5 & 6 & 200 \\
\hline 4 & Ventilation and air conditioning & 6 & 9 & 15 & 3 & 5 & 8 & 188 \\
\hline 5 & $\begin{array}{l}\text { Building services automation } \\
\text { system }\end{array}$ & 9 & 7 & 16 & 4 & 5 & 9 & 178 \\
\hline 6 & IT \& $\mathrm{C}$ facility and services & 8 & 6 & 14 & 3 & 5 & 8 & 175 \\
\hline 7 & Lifts/escalator and controls & 5 & 8 & 13 & 3 & 5 & 8 & 163 \\
\hline 8 & Lighting & 4 & 3 & 7 & 3 & 5 & 8 & 88 \\
\hline 9 & $\begin{array}{l}\text { Conference and meeting } \\
\text { facility }\end{array}$ & 1 & 3 & 4 & 3 & 5 & 8 & 50 \\
\hline 10 & Reserve electric power & 7 & 3 & 10 & 3 & 5 & 8 & 125 \\
\hline 11 & Security and safety control & 6 & 5 & 11 & 3 & 5 & 8 & 138 \\
\hline 12 & $\begin{array}{l}\text { Structural monitoring and } \\
\text { control }\end{array}$ & 4 & 4 & 8 & 3 & 5 & 8 & 100 \\
\hline 13 & Fire detection and resistance & 4 & 3 & 7 & 4 & 4 & 8 & 88 \\
\hline 14 & Heating services & 7 & 9 & 16 & 3 & 5 & 8 & 200 \\
\hline 15 & Flushing water system & 6 & 4 & 10 & 3 & 5 & 8 & 125 \\
\hline 16 & Drainage & 2 & 1 & 3 & 2 & 5 & 7 & 43 \\
\hline 17 & External decoration & 5 & 6 & 11 & 4 & 5 & 9 & 122 \\
\hline 18 & Internal decoration & 4 & 4 & 8 & 3 & 5 & 8 & 100 \\
\hline 19 & Lavatory accommodation & 4 & 5 & 9 & 3 & 5 & 8 & 113 \\
\hline 20 & Refuse collection & 5 & 4 & 9 & 3 & 5 & 8 & 113 \\
\hline 21 & Waste disposal & 1 & 2 & 3 & 1 & 2 & 3 & 100 \\
\hline 22 & Potable water system & 5 & 3 & 8 & 3 & 5 & 8 & 100 \\
\hline
\end{tabular}




\begin{tabular}{|c|c|c|c|c|c|c|c|c|}
\hline & Indicator & $S E C_{i, 1}$ & $S E C_{i, 2}$ & $S E C_{i}$ & $S T C_{i, 1}$ & $S T C_{i, 2}$ & $S T C_{i}$ & $E T I_{i}$ \\
\hline 23 & Circulation for disabled & 5 & 5 & 10 & 4 & 5 & 9 & 111 \\
\hline 24 & Car park/transportation facility & 2 & 3 & 5 & 2 & 5 & 7 & 71 \\
\hline 25 & Entertainment facilities & 1 & 4 & 5 & 2 & 5 & 7 & 71 \\
\hline 26 & External landscape & 2 & 3 & 5 & 2 & 5 & 7 & 71 \\
\hline 27 & Property management & 1 & 5 & 6 & 2 & 5 & 7 & 86 \\
\hline 28 & Cleanliness & 4 & 3 & 7 & 3 & 5 & 8 & 88 \\
\hline 29 & Building architecture design & 4 & 2 & 6 & 4 & 1 & 5 & 120 \\
\hline 30 & Green design & 6 & 2 & 8 & 4 & 5 & 9 & 89 \\
\hline 31 & Computer aided design & 5 & 2 & 7 & 4 & 5 & 9 & 78 \\
\hline 32 & $\begin{array}{c}\text { Computer aided } \\
\text { construction/installation }\end{array}$ & 2 & 8 & 10 & 4 & 5 & 9 & 111 \\
\hline 33 & Computer aided manufacturing & 8 & 1 & 9 & 4 & 5 & 9 & 100 \\
\hline 34 & Means of escape & 1 & 1 & 2 & 3 & 5 & 8 & 25 \\
\hline 35 & Usable areas & 1 & 1 & 2 & 2 & 5 & 7 & 29 \\
\hline 36 & Environmental friendliness & 1 & 2 & 3 & 1 & 5 & 6 & 50 \\
\hline 37 & Extensive use of artificial & 4 & 2 & 6 & 4 & 5 & 9 & 67 \\
\hline 38 & Existence of green features & 1 & 1 & 2 & 1 & 5 & 6 & 33 \\
\hline 39 & Access sign and directory & 1 & 1 & 2 & 1 & 5 & 6 & 33 \\
\hline 40 & Maintainality & 1 & 1 & 2 & 1 & 5 & 6 & 33 \\
\hline 41 & Flexibility for renovation & 4 & 3 & 7 & 2 & 5 & 7 & 100 \\
\hline 42 & Electromagnetic compatibility & 3 & 1 & 4 & 2 & 5 & 7 & 57 \\
\hline 43 & Thermal comfort and indoor air & 5 & 8 & 13 & 3 & 5 & 8 & 163 \\
\hline
\end{tabular}

Table 3. Gann's square of nine for KPI identification

\begin{tabular}{|l|c|c|c|c|c|c|c|c|c|}
\hline & 1000 & 990 & 980 & $\mathbf{9 7 0}$ & 960 & 950 & 940 & 930 & $\mathbf{9 2 0}$ \\
\hline $\mathbf{6 6 0}$ & 650 & 640 & 630 & $\mathbf{6 2 0}$ & 610 & 600 & 590 & $\mathbf{5 8 0}$ & 910 \\
\hline 670 & $\mathbf{3 8 0}$ & 370 & 360 & $\mathbf{3 5 0}$ & 340 & 330 & $\mathbf{3 2 0}$ & 570 & 900 \\
\hline 680 & 390 & $\mathbf{1 8 0}$ & 170 & $\mathbf{1 6 0}$ & 150 & $\mathbf{1 4 0}$ & 310 & 560 & 890 \\
\hline 690 & 400 & 190 & $\mathbf{6 0}$ & $\mathbf{5 0}$ & $\mathbf{4 0}$ & 130 & 300 & 550 & 880 \\
\hline $\mathbf{7 0 0}$ & $\mathbf{4 1 0}$ & $\mathbf{2 0 0}$ & $\mathbf{7 0}$ & $\mathbf{2 0}$ & $\mathbf{3 0}$ & $\mathbf{1 2 0}$ & $\mathbf{2 9 0}$ & $\mathbf{5 4 0}$ & $\mathbf{8 7 0}$ \\
\hline 710 & 420 & 210 & $\mathbf{8 0}$ & $\mathbf{9 0}$ & $\mathbf{1 0 0}$ & 110 & 280 & 530 & 860 \\
\hline 720 & 430 & $\mathbf{2 2 0}$ & 230 & $\mathbf{2 4 0}$ & 250 & $\mathbf{2 6 0}$ & 270 & 520 & 850 \\
\hline 730 & $\mathbf{4 4 0}$ & 450 & 460 & $\mathbf{4 7 0}$ & 480 & 490 & $\mathbf{5 0 0}$ & 510 & 840 \\
\hline $\mathbf{7 4 0}$ & 750 & 760 & 770 & $\mathbf{7 8 0}$ & 790 & 800 & 810 & $\mathbf{8 2 0}$ & 830 \\
\hline
\end{tabular}

Second, some of the energy and time consumption score data in Table 2 are questionable. Based on common senses, indicators No. 4-9 (ventilation and air conditioning, building services automation system, IT \& C facility and services, lifts/escalator and controls, and lighting) are components of indicator No. 3 (electricity and electrical services). However, Table 2 shows the SEC and STC for indicator No. 3 is even less than those of its components, for example, indicators No. 5 and No. 
6. The problem is that some indicators in Table 2, which include but not limited to indicators No. 3-9, are not in the same level in the hierarchy in terms of energy consumption, but are put in the same level. Besides, embodied energy is the energy consumed by the procedures associated with the mining, production, delivery, and construction of building materials and building components. Maintainality, flexibility for renovation, electromagnetic compatibility, and thermal comfort and indoor air quality (indicators No. 40-43) are neither building materials nor building components, thus do not carry embodied energy, $S E C_{i, 1}$ or $S T C_{i, 1}$.

The last but not the least, according to Eq. (3), all the numbers in the last column in Table 2 are incorrect, as they are overstated by 100 times. For example, the ETI value for "construction materials", the 1 st indicator in Table 2 should be 1.78 , rather than 178 . For this reason, the relevance of the Gann's square of nine in Table 3 with the purpose of identifying their KPI requires more study, as all the ETI in Table 2 should be in the scope of 0.25 to 2.00 , while the numbers in Table 3 are in the scope of 20 to 1000 .

\section{Their ANP method}

The researchers used the analytical network process (ANP) method to derive the weighting for factors selected from Tables $2 \& 3$. ANP is one of the many multi-criteria decision making (MCDM) techniques. It is usually deployed to derive weightings for a range of variables when multiple criteria have to be considered, so variables with different units can be compared subjectively [11]. In the ETI approach, there is only one (not several) criterion for indicator selection, that is, energy consumption rates of building materials/ components. Energy consumption rate of any building materials/ components can be expressed in terms of $\mathrm{J} / \mathrm{S}$ or $\mathrm{W}$. Hence, ANP is not relevant at all.

\section{Their assumptions}

The ETI approach in [8] did not address the impact of energy consumption patterns of the building occupants, or the impact of the geographical location of a building on its energy consumption rate. In addition, the ETI based indicator selection process in [8] suggested that a building component with a lower embodied energy was more intelligent than that with a higher one, which is questionable too, as transportation cost energy, and it has little to do with "building intelligence". For example, almost all the building materials consumed in the construction industry in Singapore are imported from overseas, thus are high in terms of embodied energy, as significant amount energy has to be consumed for sea freight. Cement, a basic building material, is mainly from China, Taiwan and Japan [12]. It is not convincing to say a building in Singapore is not intelligent simply because it is not constructed in China.

\section{SENSOR BASED REAL TIME IB ASSESSMENT (SBR) MODEL}

\section{The model}

As suggested earlier, the model of Chen et al. [8] did not cover the entire life span of a building. Indeed, it is very hard, if not possible, to collect embodied energy data for a particular building. Besides, the existing IB assessment can only be done manually, and seldom consider the responses of occupants. CIBSE [13] suggests that the main factors that influence comfort for people relate broadly to our senses, that is, touch, smell, vision and hearing. Thus an IB should at least provide a good thermal environment, fresh air and good light. Hence, the aim of this paper is to develop a sensor based real time office building energy effectiveness assessment model. The model focuses on the building operation stage, and examines the energy effectiveness by considering energy consumption of a building and comfort of its occupants. The model is presented in Figure 1.

The model assesses the energy performance of a building by a well-being cost index. It reads nine variables, which covering thermal quality, illumination quality, air quality and the response of occupants. The well-being cost index is derived from the energy consumption index and indoor climate index. The energy consumption index is derived from indoor air temperature, outdoor air temperature, energy (electricity, fuel and gas) consumption, and energy consumption rates recommended by the building regulations. It 


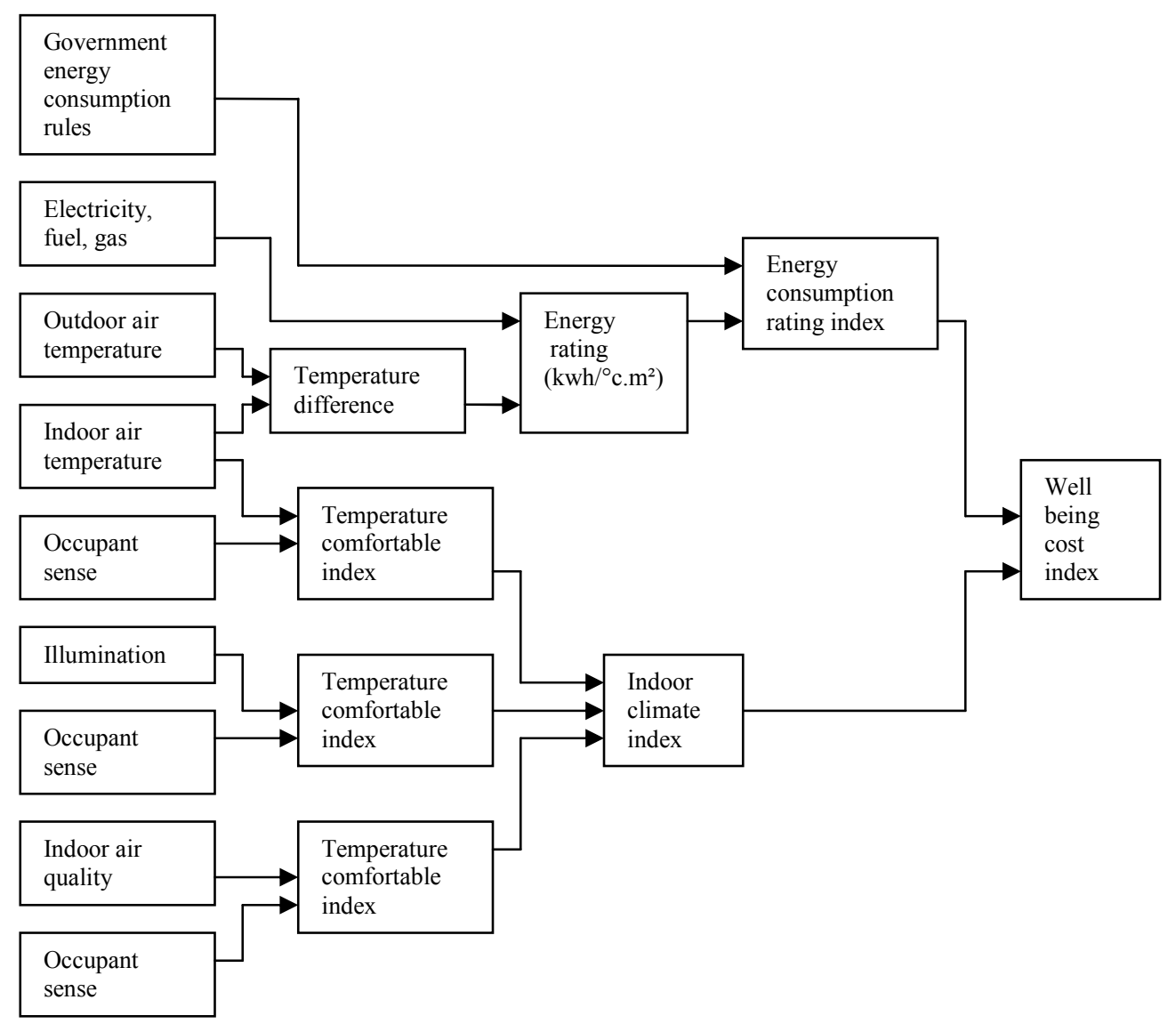

Figure 1. Real time building intelligence assessment model

measures the effectiveness of the performance of a building. The indoor climate index measures physical working environment and the response of the occupants. Whilst data for energy consumption, temperature, humidity, illumination can be captured by traditional sensors, the feedback of occupants may be captured by sense diary, shown in Figure 2. The sense diary is a touch screen electronic device [14]. It can record the date, and the satisfactory level of the occupants on temperature, lighting, sound and indoor air quality.

Figure 1 also illustrates how energy consumption index, temperature comfortable index, humidity comfortable index, lighting comfortable index, indoor air quality comfortable index and indoor climate index can be derived by using the data from sensors. Two key tasks in the model are to drive the cost weighting and the weightings of the sub-factors of the indoor climate index. The are explained hereunder.

\section{Cost weighting}

Energies in office buildings are mainly consumed by heating, ventilation, air-con, lighting facilities. These facilities work together and aim to provide a health built environment for the occupants of the buildings. It is estimated that approximately 40 per cent of the existing building stock are sick buildings and are creating sick building syndrome (SBS) for their occupants [15]. The studies of Weinstein [16], Wyon [17], Wyon et al.[18], Boyce et al. [19], Nunes et 
al.[20], Banhidi et al.[21], Fisk and Rosenfeld [22] have addressed the relationship between ventilation, temperature, lighting and noise on the performance of workers and suggest that these environment factors can negatively affect the worker productivity. Because inadequate ventilation or superfluous emissions from different sources increase the concentration of pollutants, thus reducing air quality. In addition, temperature, lighting, noise can affect the well-being of occupants. Reduced air quality and ill-being can negatively affects the central nervous system of the occupants, increasing SBS symptoms such as headache, difficulty in concentration, tiredness. The SBS symptoms can cause distraction from work and productivity loss [25-26].

Baker et al.[23] and Fisk and Rosenfeld [22] suggest that a linear relationship exists between SBS and self-estimated productivity. Baker et al. [23] suggest that the workers presenting with more SBS symptoms were found to respond 7 per cent longer in a continuous performance task and have 30 per cent higher error rate in a symbol-digit substitution test. Fisk and Rosenfeld [22] estimate that an average decrement in the self-reported productivity of 2 per cent for those occupants with two SBS symptom. Deficient building environment (sick buildings) and SBS symptoms affect not only the worker effectiveness but also their health, giving rise to high social costs. According to the report of US technologies, State and Community programs, poor health and lost productivity associated with office environment alone cost US business more than $\$ 438$ billion per year [1].

The trade-off between energy consumption rating index and the indoor climate index is thus a complicate issue. Whilst energy efficiency is a crucial issue in petrochemical, automobile, power plant industries where energy consumption is high; the indoor climate, which linked to productivity, is probably more important than energy efficiency for office buildings [27], as the salaries of workers in typical office buildings exceed the building energy by approximately a factor of 100 [28-29]. Hence, even a 1 per cent increase in productivity should be sufficient to cover any expenses related to energy costs [27].

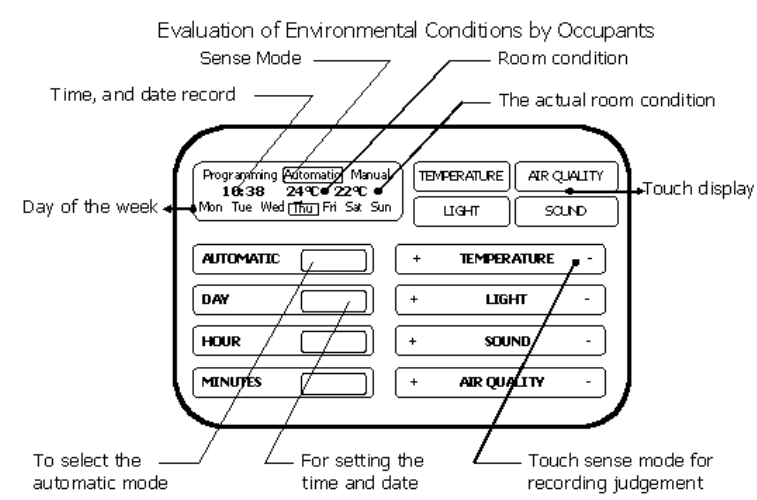

Figure 2. Sense diary [14]

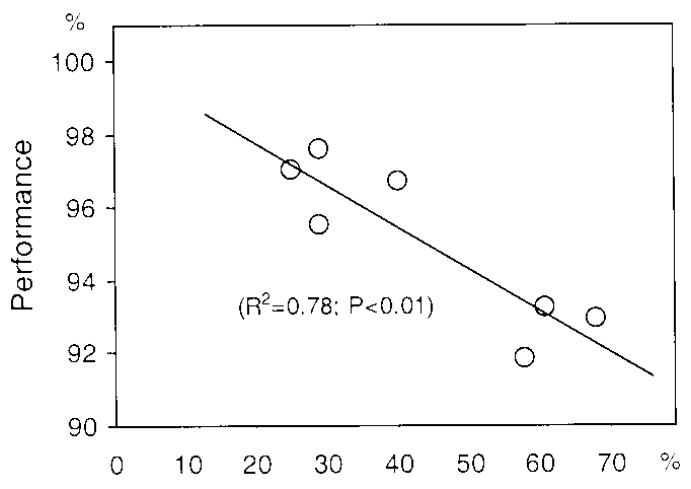

Figure 3. Productivity loss versus dissatisfied indoor climate [30]

In our model, the weighting for energy consumption rating index and the indoor climate index is calculated based on the cost of energy, and the cost of productivity loss due to uncomfortable indoor climate. The relationship between dissatisfied indoor climate and productivity loss is presented in Figure 3 [30]. Productivity is linked to salary of employees. Energy consumption is linked to operational costs. Hence, weightings is calculated objectively. Traditionally, weightings between comfort and economy criteria are assigned subjectively [31].

\section{Weightings of the indoor climate index}

The weightings of the sub-factors of the indoor climate index can be derived by using multi-criteria decision making techniques, for example, multiattribute value technique (MAVT). The MAVT has 
been well explained in text books in the field of decision science, thus is not be elaborated here.

\section{Procedures}

To implement the model, five steps may be followed:

- To identify candidate office buildings;

- To develop and install the sensor networks including the sense diary in the office buildings;

- To calculate the cost weightings for the energy consumption index and the indoor climate index;

- To calculate the weightings for the temperature comfortable index, humidity comfortable index, lighting comfortable index, and indoor air quality comfortable index; and

- To calculate the well-being cost index.

\section{An experimental case study}

The project, with its web site at www.cmips.org.uk/members.htm, has four partners. The industry partners are responsible for setting up the sensor networks and data visualization. The authors are responsible for developing the building energy effectiveness assessment models. Field data are not available at this stage. Hence, an experimental case study is provided for the industry partners to demonstrate how the model can be deployed to assess the energy effectiveness of a building. Two rooms in the same office building are selected. The cost weighting is calculated based on the study of Wyon and Wargocki [30]. The weighting of temperature comfortable index, humidity comfortable index, lighting comfortable index, and indoor air quality index are derived by survey experts and using MAVT. Sample data of the indexes and their weightings are presented in Table 4. Room A scores higher than Room B. The weightings of the energy consumption index and indoor climate index further suggest that it is not appropriate to ignore the response of occupants when assessing the energy effectiveness of a building, as the weighting of energy consumption index is far less than that of the indoor climate index, which related to occupants responses.
Table 4. Well-being cost index of office Rooms A and $\mathrm{B}$

\begin{tabular}{|c|c|c|c|c|}
\hline & & & $\begin{array}{l}\varangle \\
\Xi \\
0 \\
ٌ\end{array}$ & 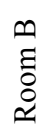 \\
\hline \multirow{2}{*}{$\begin{array}{l}\text { Energy } \\
\text { con. } \\
\text { index }\end{array}$} & \multirow{2}{*}{ Energy } & Weighting & \multicolumn{2}{|c|}{0.1} \\
\hline & & Score & 90 & 80 \\
\hline \multirow{8}{*}{$\begin{array}{l}\text { Indoor } \\
\text { climate } \\
\text { index }\end{array}$} & \multirow{2}{*}{$\begin{array}{c}\text { Temperature } \\
\text { comfortable index }\end{array}$} & Weighting & \multicolumn{2}{|c|}{0.3} \\
\hline & & Score & 80 & 70 \\
\hline & \multirow{2}{*}{$\begin{array}{c}\text { Humidity } \\
\text { comfortable index }\end{array}$} & Weighting & \multicolumn{2}{|c|}{0.2} \\
\hline & & Score & 80 & 70 \\
\hline & \multirow{2}{*}{$\begin{array}{c}\text { Lighting } \\
\text { comfortable index }\end{array}$} & Weighting & \multicolumn{2}{|c|}{0.2} \\
\hline & & Score & 80 & 70 \\
\hline & \multirow{2}{*}{$\begin{array}{c}\text { Indoor air } \\
\text { comfortable index }\end{array}$} & Weighting & \multicolumn{2}{|c|}{0.2} \\
\hline & & Score & 80 & 70 \\
\hline \multicolumn{3}{|c|}{ Well-being cost index } & 81 & 71 \\
\hline
\end{tabular}

\section{CONCLUSIONS}

The existing building intelligence assessment models seldom consider the responses of the occupants in the building. Besides, these models can only be conducted manually, thus can hardly provide timely assistance for facilities manager to improve and maintain their facilities. After a critical review of the models in a previous published paper regarding building energy intelligence assessment, this study develops a sensor based real time office building energy effectiveness assessment model. The new model considers both the building energy consumption and the responses of its occupants, and can provide feedback to the occupants or the facility manager to monitor the energy effectiveness of the building, thus improving the maintenance performance. A case study demonstrates how the model can be applied in real life.

\section{ACKNOWLEDGEMENTS}

The authors would like to thank Mr Richard Egan in Thales Research and Development (UK), and Professor Derek Clements-Croome in the University of Reading (UK) for their support and encouragements. The project, entitled "Co-ordinated Management of Pervasive Intelligent Space", is 
founded by Department of Trade and Industry (DTI) in UK. The project number is TP/3/PIT/6/1/16218.

\section{REFERENCE}

[1] Gassmann, O. and Meixner, H. (2004). Sensors in intelligent buildings: Overview and trends, in Gassmann and Meixner (editors) Sensors in Intelligent Buildings, volume 2, 3-25.

[2] Clements-Croome, D.J. (2004). Intelligent buildings: design, management and operation. Thomas Telford, London.

[3] SCC, Shanghai Intelligent Building Appraisal Specification, Shanghai Construction Council (SCC), Shanghai, China, 2002.

[4] CABA, Building IQ Rating Criteria. Task Force 1 Intelligent Building Ranking System, Continental Automated Building Ranking System, Continental Automated Building Association (CABA), Ottawa, Canada, 2004.

[5] AIIB, IB Index, third ed., Asian Institute of Intelligent Buildings (AIIB), Hong Kong, 2005.

[6] R. Bassi , "MATOOL: A matrix tool for assessing the performance of intelligent buildings," Proceedings of the BRE Seminar on Intelligent Buildings, Building Research Establishment Ltd., UK, 2005.

[7] DQI, "The catalyst for providing better buildings," http://www.dqi.org.uk/DQI/default.htm, The Design Quality Indicator (DQI) website, retrieved in Sep. 2006.

[8] Z. Chen, D. Clements-Croome, J. Hong, H. Li and Q. $\mathrm{Xu}$, "A multi-criteria lifespan energy efficiency approach to intelligent building assessment," Energy and Buildings, 38 (5), 393-409, 2006.

[9] Shen, L.Y., Wu, M., and Wang, J.Y. (2002). A model for assessing the feasibility of construction project in contributing to the attainment of sustainable development, Journal of Construction Research, Vol. 3 No. 2, pp. 255-270.

[10] Smith, D.K. (2000). Total life-cycle cost model (presentation), Facility Information Council, National Institute of Building Sciences, USA, http://nibs.org/Tlcm/TotalLifeCycle20000B. pdf, June 2006

[11] Satty, T.L. (1996). The analytical network process, RWS Publication.

[12] Wu, M. (2004). Modelling Just-In-Time Purchasing in the Reading Mixed Concrete Industry, Unpublished PhD thesis, the National University of Singapore.
[13] CIBSE (2006). Comfort, The Chartered Institute of Building Service Engineer, The CIBSE knowledge series KS6.

[14] Clements-Croome, D.J., Wu, M. and Li, S.R. (2006), A sensor based intelligent building assessment model, in Proceedings of Chinese Research Institute of Construction Management 2006 Annual Conference, Beijing, China, $3^{\text {th }}-8^{5 \mathrm{~h}}$ Nov., pp.91-99.

[15] Wyon, D.P. (1996). Indoor environmental effects on productivity. In Proceedings of IAQ'96 Paths to Better

[16] Weinstein, N.D. (1974). Effects of noise on intellectual performance, Journal of Applied Psychology, 59(5), 548-554.

[17] Wyon, D.P. (1974). The effects of moderate heat stress on typewriting performance. Ergonomics, 17(3), 309-318.

[18] Wyon, D.P., Andersen, I. and Lundquist, G.R. (1979). The effects of moderate hear stress on mental performance. Scandinavian Journal of Work Environment and Health, 5, 352-361.

[19] Boyce, P.R., Berman, S.M., Collins, B.L., Lewis, A.L., and Rea, M.S. (1989). Lighting and Human Performance: A Review. Lighting equpiment division National Electrical Manufactures Association and Lighting Research Institute, 5-54.

[20] Nunes. F., Menzies, R., Tamblyn R.M., Boehm, E. and Letz, R. (1993). The effect of varying level of outdoor air supply on neurobehavioural performance function during a study of sick building syndrome (SBS). In Proceedings of Indoor Air '93, The $6^{\text {th }}$ International Conference on Indoor Air Quality and Climate, Helsinki, Finland, Helsinki University of Technology, 1, 53-58.

[21] Banhidi, L., Antalovits, M., Dombi, I., Izso, LO, Lang, E., Magyar, Z., Majors, A., Mitsanyi, A. and Molnar, L.(1996). A new psychological, ergonomic measurement method fo the combined effect of heat, noise and lighting on mental performance. In Proceedings of Indoor Air '96, The $7^{\text {th }}$ International Conference on Indoor Air Quality and Climate, Nagoya, Japan, Institutue of Public Health, 1(1), 1013-1018.

[22] Fisk, W.J. and Rosenfeld, A.H. (1997). Estimate of improved productivity and health from better indoor environments. Indoor Air, 7, 158-172.

[23] Baker, E.L., Letz, R.E., Shala, S., Plantamura, D. and Lyndon, M. (1985). A computer based neurobehavioral evaluation system for occupaniional and environmental epidemiology: Methodology and 
valiation studies. Neurobehavioral Texicology and Teratology, 7, 369-377.

[24] Wargocki, P., Wyon, D.P., Baik, Y.K., Clausen, G. and Fanger, P.O. (1999). Perceived air quality, sick building syndrome (SBS) symptoms and productivity in an office with two different pollution loads. Indoor Air, 9(3), 165-179.

[25] Wargocki, P., Wyon, D.P., Baik, Y.K., Clausen, G. and Fanger, P.O. (2000). The effects of outdoor air supply rate in an office on perceived air quality, sick building syndrome (SBS) symptoms and productivity in an office. Indoor Air, 10(4), 222-236.

[26] Lagercrantz, L., Wistrand, M., Willen, U., Wargocki, P., Witterseh, T., and Sundell, J. (2000). Negative impact of air pollution on productivity: Previous Danish findings repeated in new Swedish test room. In Proceedings of Healthy Building 2000, Espoo, Finland, 1, 653-658.

[27] Zsolt, B.B. (2005). Human perception, SBS symptomos and performance of office work during exporsure to air polluted by building materials and personal computers, unpublished $\mathrm{PhD}$ thesis, International Centre for Indoor

[28] Woods, J.E. (1989). Cost avoidance and productivity in owning and operating buildings. Occupational Medicine, 4(4) 753-770. Building Environments, USA, ASHRAE, 5-15.

[29] Skaret, J.E. (1992). Indoor environment and economics. Project no. N 6405, The Norwegian Institute of Building Research (NBI-Byggforsk), Oslo (in Norwegian).

[30] Wyon, D.P. and Wargocki, P. (2005). Indoor Air Quality Effects on Office Work, in Creating the Productive Workplace, edited by Clements-Croome.

[31] Bernard, T. and Kuntze, H.B. (2004). Sensor-based management of energy and thermal comfort, in Gassmann and Meixner (editors) Sensors in Intelligent Buildings, vol. 2, 103-126.

\section{THE COMPUTER CODES}

The codes, written in Java, are for computing the well being cost index.

/*

Compute the overall index at a point with formatting

using standard input and output

Author: Min Wu */

File: PointAssessment.java

import java.util.*; import java.text.*;

class PointAssessment \{

public static void main( String[] args ) \{

double T, Tindex, L, Lindex, RH, Hindex, Pindex;

Scanner scanner;

DecimalFormat df = new DecimalFormat("0.00");

scanner $=$ new Scanner(System.in);

//Get input

System.out.print("Enter T: ");

$\mathrm{T}=$ scanner.nextDouble () ;

System.out.print("Enter L: ");

$\mathrm{L}=$ scanner.nextDouble();

System.out.print("Enter RH: ");

$\mathrm{RH}=$ scanner.nextDouble();

//Compute temperature index

if $((\mathrm{T}<0) \|(\mathrm{T}>36))$

$\{$ Tindex $=0.0$;

else

$\{$ if $(\mathrm{T}<16)$

$\{$ Tindex $=(15.0 / 4.0) * \mathrm{~T} ;\}$

else

$\{$ if $(\mathrm{T}<20)$

$\{$ Tindex $=10.0 *(T-16)+60.0 ;\}$

Else

$\{\operatorname{if}(\mathrm{T}<24)$

$\{$ Tindex $=100.0 ;\}$

else

$\{\operatorname{if}(\mathrm{T}<30)$

$\{$ Tindex $=(-20.0 / 3.0) * \mathrm{~T}+260.0 ;\}$

else

$\{$ Tindex $=-10.0 * \mathrm{~T}+360.0 ;\}\}\}\}$

//Compute lighting index

if $((\mathrm{L}<0.0) \|(\mathrm{L}>2500.0))$

$\{$ Lindex $=0.0 ;\}$

else

$\{$ if $(\mathrm{L}<500.0)$

$\{$ Lindex $=0.2 * \mathrm{~L} ;\}$

else

$\{\mathrm{if}(\mathrm{L}<2000.0)$

$\{$ Lindex $=100.0 ;\}$

Else

$\{$ Lindex $=(-0.2) * \mathrm{~L}+500.0 ;\}\}\}$

//Compute humidity index

if $((\mathrm{RH}<0.0) \|(\mathrm{RH}>1.0))$

$\{$ Hindex $=0.0 ;\}$

else

\{if $(\mathrm{RH}<0.3)$

$\{$ Hindex $=(1000.0 / 3.0) * \mathrm{RH}$; \} 
else

$\{\operatorname{if}(\mathrm{RH}<0.7)$

$\{$ Hindex $=100 ;\}$

else

$\{$ Hindex $=(-1000.0 / 3.0) * \mathrm{RH}+(1000 / 3.0) ;\}\}\}$

Pindex $=(1.0 / 3.0) *$ Tindex $+(1.0 / 3.0) *$ Lindex $+(1.0 / 3.0$

)*Hindex;

//Display the results

System.out.println("'");

System.out.println("Given T: " + T);

System.out.println("Tindex: " + df.format(Tindex));
System.out.println(""");

System.out.println("Given L: " + L);

System.out.println("Hindex: " + df.format(Lindex));

System.out.println("'");

System.out.println("Given RH: " + RH);

System.out.println("Hindex: " +

df.format(Hindex));

System.out.println("'");

System.out.println("Pindex: " + df.format(Pindex)); \}) 